\title{
Association of ENPP1 (K121Q rs 1044498) and TCF7L2 (C/T rs7903146) Gene Polymorphisms with Type2 Diabetes in Zanjan Population (Northwest, Iran)
}

\author{
Pourandokht Golbon $^{1}$ (D), Abdolreza Esmaeilzadeh ${ }^{2,3,4}$ iD, Sanaz Mahmazi $^{\text {1* }}$ (iD \\ 1. Dept. of Genetics, Faculty of Basic Sciences, Zanjan Branch, Islamic Azad University, Zanjan, Iran \\ 2. Dept. of Immunology, Faculty of Medicine, Zanjan University of Medical Sciences, Zanjan, Iran \\ 3. Metabolic Diseases Research Center, Zanjan University of Medical Sciences, Zanjan, Iran \\ 4. Cancer Gene Therapy Research Center, Zanjan University of Medical Sciences, Zanjan, Iran
}

\begin{tabular}{l}
\hline Article Info \\
\hline doi 10.30699/jambs.26.118.9 \\
\hline $\begin{array}{l}\text { Received: 2018/11/13; } \\
\text { Accepted: 2018/04/16; } \\
\text { Published Online: 01 Sep 2018; }\end{array}$ \\
Use your device to scan and read the \\
article online \\
口. \\
\hline
\end{tabular}

Corresponding Information: Sanaz Mahmazi, Dept. of Genetics, Faculty of Basic Sciences, Zanjan Branch, Islamic Azad University, Zanjan, IranEmail: sanazmahmazi@yahoo.com

\begin{abstract}
Background \& Objective: Ecto-nucleotide pyrophosphatase/phosphodiesterase 1 (ENPP1) is a class II membrane glycoprotein that binds to insulin $\alpha$ receptor and can interfere in insulin signaling pathway. Transcription factor-7-like 2 (TCF7L2) is a transcription factor which plays a critical role in pancreatic $\beta$ cell activity. ENPP1 and TCF7L2 gene polymorphisms may have functional role in susceptibility to type 2 diabetes (T2D). The aim of this study was to investigate the association of reported K121Q and C/T rs7903146 variants of ENPP1 and TCF7L2 genes with the risk of T2D in our population.
\end{abstract}

Materials \& Methods: 240 T2D and 240 healthy subjects were recruited. Genotyping was carried out by PCR-RFLP method. T-test was used for association study.

Results: ENPP1 121Q (CC) genotype was significantly higher in T2D comparing to controls (OR;1.61, 95\% CI;1.02-2.55, $P=0.02)$ and a significant association between the frequency of $\mathrm{C}$ allele and T2D was observed (OR;1.339, 95\%CI;1.04$1.72, P=0.012$ ). TT genotype of TCF7L2 C $>\mathrm{T}$ rs7903146 was significantly higher in T2D patients (OR;0.67, 95\% CI;0.49-0.98, $P=0.02)$, but the T allele could not significantly affect the risk for T2D in our population.

Conclusion: The high frequency of Q allele of the ENPP1 K121Q and TT genotype of the TCF7L2 might be considered as a predisposing factor for T2D.

Keywords: Diabetes Mellitus, Type 2, Ectonucleotide pyrophosphatase phosphodiesterase 1, Polymorphism, Transcription Factor 7-Like 2, PCR-RFLP

\section{Introduction}

Type 2 Diabetes (T2D) is a progressive multifactorial disease influenced by environmental and genetic factors and can be controlled or prevented if genetic factors are identified, and by changing the environment and lifestyle (1). T2D is a metabolic disease characterized by increase in blood glucose levels, but the cause of increased blood sugar is different in different patients. The main factor controlling and regulating blood sugar is the insulin hormone, which is secreted from pancreatic $\beta$ cells and acts on cells in different tissues, helping to match the glucose uptake by them, and glucose increase is observed when glucose uptake by cells becomes difficult (2). T2D disease occurs if the levels of insulin secretion decrease for any reason or the cells do not respond properly to insulin secretion and show resistance to it (3). Changes in all genetic factors that play a role in regulating the function of the pancreatic $\beta$ cells in the pathway for the production and secretion of insulin are good candidates for examination as a cause of diabetes (4). But the study of genetic and environmental factors that regulate the response of cells to insulin are also important because they lead to insulin resistance and cause T2D (5). Several genes have been investigated in this regard. In some cases, T2D has been suggested as a single-gene disease, but it is believed to be polygenic. Presence of more than $50 \%$ T2D occurrence in the children of an affected parent, strengthens the importance of evaluating different candidate genes (6). Determining the genes involved in the onset of diabetes could help define the pathway of disorder leading to diabetes; in that case, appropriate and effective treatment strategies can be identified, and even preventive strategies can be developed (1).

Some genes polymorphisms are associated with impaired pancreatic $\beta$ cell function in the secretion of insulin. The TCF7L2 (Transcription factor 7-like 2) gene is located on the long arm of chromosome 10 (10q25.2-q25.3) and has 17 exons and 16 introns. Among the 17 exons of this gene, 4, 13, 15 and 16 can create different isoforms with alternative splicing, and 
about 20 different isoforms have been isolated from different cells. In the process of splicing, the polymorphisms of intron IV (IVS IV) are of great importance (7). Studies have shown that the variants of TCF7L2 regulate the expression of various genes in the signaling of the Wnt path. In the intestine, it regulates the expression of the proglucagon gene and the GLP-1 hormone (glucagon like peptide-1). GLP-1 is an incretin hormone that stimulates the secretion of insulin by pancreatic cells after food intake (8).

The ENPP1 gene (Ectonucleotide Pyrophosphatase/ Phosphodiesterase) is located on the long arm of chromosome 6 (6q22-q23), which has 25 exons and 24 introns. The product of this gene is an endogenous transmembrane glycoprotein that can inhibit the signaling of the insulin receptor (9). ENPP1 disrupts insulin signaling in various peripheral tissues such as the liver, muscle, fat, and pancreas by inhibiting tyrosine kinase activity of the insulin receptor and somehow causing insulin resistance (10). The ENPP1 protein contains 925 amino acids. Various studies have shown that the amino acid 121 of this protein, coded by the gene's exon 4 , is important for its binding to the insulin receptor and the inhibition of its function. If the amino acid 121 is gln (Q), its inhibitory power will be greater than when the lys $(\mathrm{K})$ amino acid is in this position (11). Therefore, K121Q polymorphism can be a predisposing factor for insulin resistance and T2D.

Considering the evidence of the importance of rs7903146 C/ T polymorphisms of TCF7L2 gene and rs1044498 K121Q of ENPP1 gene, this study investigated these two polymorphisms in patients with T2D in Zanjan.

\section{Materials and Methods}

In this case-control study, 240 T2D patient and 240 healthy control subjects referred to the Diabetes Clinic entered the study after evaluation by an endocrinologist and necessary ethical clearances.

The diabetic index was considered in accordance with the WHO criteria for fasting blood glucose above $126 \mathrm{mg} / \mathrm{dL}$ and HbA1C higher than 6.5. All the selected subjects were over 35 years of age, and $1 \mathrm{~mL}$ of blood sample was taken after obtaining an informed written consent from patients.
DNA extraction was performed from all blood samples containing EDTA at the genetic laboratory of Zanjan Islamic Azad University Research Center with the Cinna Pure DNA extraction kit (Sina Clone Iran). In all the samples, an exon region of the ENPP1 gene and an intron region of TCF7L2 were amplified by the PCR method by using specific primer pairs (Table 1).

A $30 \mu \mathrm{L}$ PCR mixture containing $50 \mathrm{ng}$ genomic DNA, $1.5 \mathrm{mmol} / \mathrm{L} \mathrm{MgCl}_{2}, 0.5 \mathrm{mmol} / \mathrm{L}$ of each dNTPs, and $0.5 \mathrm{pmol}$ of each primer were prepared.

The PCR cycles consisted of an initial denaturation at $95^{\circ} \mathrm{C}$ for $5 \mathrm{~min}$., followed by 35 cycles of denaturation at $94^{\circ} \mathrm{C}$ for $30 \mathrm{~s}$, annealing at $58^{\circ} \mathrm{C}$ for 1 min $\mathrm{s}$ and elongation at $72^{\circ} \mathrm{C}$ for $30 \mathrm{~s}$. The final extension step occurred at $72^{\circ} \mathrm{C}$ for $5 \mathrm{~min}$.

PCR-RFLPs were performed for genotype analysis - 238bp PCR products of the ENPP1 exon 4 fragment for the analysis of K121Q (A/C) polymorphism was digested with AvaII (Thermo Fisher Scientific). A allele was not digested and gave $238 \mathrm{bp}$ fragment and C allele cleaved to 148bp and 90bp fragments (Table 1$)$.

A 266bp PCR product of the TCF7L2 IVS IV fragment for rs7903146 C/T polymorphism detection was digested with RsaI (Thermo Fisher Scientific). RsaI cleaved $\mathrm{C}$ allele and gave 233 and $33 \mathrm{bp}$ fragments. $\mathrm{T}$ allele was not digested (Table 1).

Genotype and allele frequencies for the studied polymorphisms were compared by Fischer's exact test. The agreement of genotype frequencies with the Hardy-Weinberg equilibrium expectation was tested using the $\mathrm{X}^{2}$ test. Continuous variables were presented as mean \pm SD and compared by T test. Statistical tests were performed by Statistical Package for Social Sciences (SPSS 18 for Windows; SPSS Inc. Chicago, IL, USA). The results were considered statistically significant when the $\mathrm{P}$-value was less or equal to 0.05 .

\section{Ethics}

This study was approved by Tabriz Islamic Azad University medical ethics group (IR.IAU.TABRIZ .REC.1395.37)

Table 1. The Specific Primers and Restriction Enzymes for rs1044498 A >C ENPP1 and rs7903146 C >T TCF7L2 Polymorphisms

\begin{tabular}{|c|c|c|c|c|c|c|}
\hline Polymorphism & $\begin{array}{l}\text { Sequence } \\
\left(5^{\prime}-3^{\prime}\right)\end{array}$ & ng TM & $\begin{array}{l}\text { Restriction } \\
\text { Enzyme }\end{array}$ & $\begin{array}{l}\text { Product } \\
\text { Size }\end{array}$ & \multicolumn{2}{|c|}{$\begin{array}{c}\text { Parts of } \\
\text { Cutting (bp) }\end{array}$} \\
\hline \multirow{2}{*}{$\begin{array}{l}\text { ENPP1 K121Q } \\
\text { rs } 1044498 \text { A }>C\end{array}$} & GCAATTCTGTGTTCACTTTGGA & \multirow{2}{*}{$58^{\circ} \mathrm{C}$} & \multirow{2}{*}{ AvaII } & \multirow{2}{*}{238} & A & 238 \\
\hline & $\begin{array}{l}\text { TTTCACTATGTATTGTTGCCAGT } \\
\text { CAGCAAACAC }\end{array}$ & & & & $\mathrm{C}$ & $\begin{array}{c}148 \\
90\end{array}$ \\
\hline \multirow{2}{*}{$\begin{array}{c}\text { TCF7L2 } \\
\text { Rs7903146 C }>\mathrm{T}\end{array}$} & $\begin{array}{c}\text { CTGAACAATTAGAGAGCTAAGCA } \\
\text { CTTTTTAGGTA }\end{array}$ & \multirow{2}{*}{$58^{\circ} \mathrm{C}$} & \multirow{2}{*}{ RsaI } & \multirow{2}{*}{226} & A & 266 \\
\hline & $\begin{array}{l}\text { TTTCACTATGTATTGTTGCCAGT } \\
\text { C AGCAAACAC }\end{array}$ & & & & C & $\begin{array}{r}233 \\
33\end{array}$ \\
\hline
\end{tabular}


Table 2. Description of Anthropometric, clinical, and metabolic data for all volunteers

\begin{tabular}{lccc}
\multicolumn{1}{c}{ Characteristics } & T2D Subjects $(\mathrm{N}=240)$ & Control $(\mathrm{N}=240)$ & P-value \\
Men & 116 & 118 & - \\
Women & 124 & 122 & 0.169 \\
Age & $58.3 \pm 12.7$ & $54.1 \pm 11.3$ & $<0.001$ \\
HbA1C \% & $8.1 \pm 1.5$ & $4.8 \pm 0.5$ & $<0.001$ \\
FBS mg/dl & $157.3 \pm 60.2$ & $81.2 \pm 13.7$ & $<0.001$ \\
Triglycerides mg/dl & $188.8 \pm 12.9$ & $139.8 \pm 38.9$ & $<0.001$ \\
Cholesterol mg/dl & $181 \pm 50.4$ & $167.1 \pm 19.6$ & 0.037 \\
HDL mg/dl & $43 \pm 8.6$ & $48.7 \pm 7.2$ & $<0.001$ \\
\hline LDL mg/dl & $126.3 \pm 31.8$ & $96.8 \pm 16.9$ & \\
\hline
\end{tabular}

*Significance $(P<0.05)$. Values are expressed as mean + standard deviation $(\mathrm{SD})$, and were compared by t-test.

\section{Results}

Descriptive statistics of the metabolic characteristics of the study population are presented in Table 2 . There were no significant differences between the mean age of both T2D and control subjects. Additionally, plasma glucose, HbA1C, total cholesterol, triglycerides, and LDL levels were significantly higher in T2D subjects $(P<0.001)$ but the T2D patients had a significantly lower mean HDL $(P=0.037)$ levels.

The genotype distribution and allelic frequencies in T2D patients and healthy controls for the ENPP1 A $>C$ K121Q polymorphism are presented in Table 3 . The studied genotype and allele frequencies were in the Hardy-Weinberg equilibrium in both T2D patients $\left(\mathrm{X}^{2}=0.026, \quad P=0.98\right)$ and healthy control groups $\left(\mathrm{X}^{2}=0.097, P=0.95\right)$. The $\mathrm{CC}$ and $\mathrm{AC}$ genotypes, and $\mathrm{C}$ allele frequencies were significantly higher in T2D patients when compared with controls (Table 3 ).

The genotype distribution and allelic frequencies in T2D patients and healthy controls for the TCF7L2 IVS IV C>T polymorphism are presented in Table 4 . The studied genotype and allele frequencies were in the Hardy-Weinberg equilibrium in both T2D patients $\left(\mathrm{X}^{2}=0.59, \quad P=0.97\right)$ and healthy control groups $\left(\mathrm{X}^{2}=0.043, \quad P=0.98\right)$. The $\mathrm{CC}$ genotype was significantly higher in normal control subjects compared to T2D patients (Table 4). TC heterozygote genotype frequency was not significantly different in T2D and normal subjects $(P>0.05)$. We did not observe any significant difference in $\mathrm{T}$ and $\mathrm{C}$ alleles' frequency among control and T2D patients (Table 4).

Table 3: Genotypic and allelic distribution of ENPP1 K121Q polymorphism in relation to T2D

\begin{tabular}{|c|c|c|c|c|}
\hline \multirow{2}{*}{ Genotypes } & \multicolumn{4}{|c|}{ Study groups } \\
\hline & T2D & Control & $P$ value & OR (CI95\%) \\
\hline AA (Lys/Lys) & $60(25 \%)$ & $86(36 \%)$ & & Reff* \\
\hline AC (Lys/Glu) & $100(42 \%)$ & $83(34 \%)$ & 0.058 & $1.433(0.92-2.24)$ \\
\hline CC (Glu/Glu) & $80(33 \%)$ & $71(30 \%)$ & 0.02 & $1.615(1.02-2.55)$ \\
\hline \multicolumn{5}{|c|}{ Allele } \\
\hline A & 0.458 & 0.531 & & Reff \\
\hline $\mathrm{C}$ & 0.542 & 0.469 & 0.012 & $1.339(1.04-1.73)$ \\
\hline
\end{tabular}

$*$ P-value $=0.005$, OR $($ CI95\% $)=1.68(1.13-2.48)$ 
Table 4: Genotypic and allelic distribution of TCF7L2 rs7903146 polymorphism in relation to T2D

\begin{tabular}{lllll} 
Genotypes & Study Groups & & & \\
& T2D & Control & P-value & OR (CI95\%) \\
CC & $62(26 \%)$ & $79(33 \%)$ & Reff* & \\
TC & $89(37 \%)$ & $93(39 \%)$ & 0.08 & $0.731(0.47-1.12)$ \\
TT & 9 & $68(28 \%)$ & 0.02 & $0.67(0.45-0.98)$ \\
Allele & $89(37 \%)$ & & & \\
C & & 0.523 & Reff & \\
T & 0.444 & 0.477 & 0.34 & $0.95(0.74-1.21)$ \\
\hline *P-value $=0.01, \mathrm{OR}(\mathrm{CI} 195 \%)=0.59(0.37-0.94))$ & & & \\
\hline
\end{tabular}

\section{Discussion}

In this study, T2D was associated with high levels of triglycerides, cholesterol, and LDL and low HDL. Dyslipidemia could be a side effect of T2D and insulin resistance but because of its importance in terms of cardiovascular disease evaluation and the controlling of lipid profiles, it is suggested for T2D patients. Diabetes is associated with a greater risk of mortality from cardiovascular diseases (CVD) (12).

Increased hepatic secretion of large triglyceride-rich VLDL and impaired clearance of VLDL appears to be of central importance in the pathophysiology of diabetic dyslipidemia (13).

T2D is a metabolic disorder characterized by increased blood glucose levels resulting from problems in insulin secretion, insulin action, or both. Cell insulin resistance plays a major role in T2D and various genetic factors, too, could cause insulin resistance (11).

Ecto-nucleotide pyrophosphatase phosphodiesterase-1 (ENPP1) is an endogenous transmembrane glycoprotein that inhibits insulin receptor signaling and could be related to insulin resistance (9). Glu (Q allele) on 121 aa position of ENPP1 is more effective in reducing insulin stimulation of IR autophosphorylation, insulin receptor substrate-1 phosphorylation, phosphatidylinositol 3-kinase activity, glycogen synthesis, and cell proliferation (11).

In this study, we investigated the significant association of Q allele in K121Q polymorphism of ENPP1 gene with T2D. QQ and KQ genotypes frequencies were significantly higher in T2D patients (Table 3).

Fajar et al., in a meta-analysis showed that 121Q allele of ENPP1 is associated with T2D risk in American, European, and African populations (10). In the Chinese population, Li et al. investigated Q allele of K121Q polymorphism associated with T2D susceptibility (14). Bhatti et al. reported that ENPP1 K121Q polymorphism was not associated with T2D in the north Indian Punjabi population. According to their results, there was no QQ genotype in their studied population and the frequency of $\mathrm{Q}$ allele was low (15).

Over expression of ENPP1 could be a factor that led to insulin resistance and T2D. Instead of over-expression, ENPP1 K121Q polymorphism, with the replacement of Lys 121 with Glu, could influence ENPP1 interaction with insulin receptor on the muscle, fat, and other cells (11). Kang et al., results showed K121 allele carriers were responsive to insulin resistance diminution by BMI (body mass index) reduction. Q121 allele carriers could adopt a different lifestyle and control blood glucose level to prevent T2D (16). Q 121 allele carriers were mostly lean and this variant was not associated with obesity (17). Obesity could be associated with insulin resistance by induction of some cytokines and hormones or augmentation of some metabolites. The ENPP1 Q121 variant affected insulin resistance by the insulin receptor influence and did not seem to be associated with risk of obesity (18).

Sortica et al. in a meta-analysis detected a significant association between ENPP1 K121Q polymorphism and increased susceptibility to Diabetic Kidney Disease (DKD) in European and Asian populations (19). Sumi et al. reported the association of the ENPP1 Q121 variant with the coronary artery disease. Most of the factors that cause insulin resistance could be a risk factor for coronary atherosclerosis (20). Then, if we evaluate ENPP1 polymorphism in T2D patients or their normal relatives, by suggesting a suitable lifestyle, diabetes can be prevented or delayed and diabetic patients screened for the possibility of other related diseases can improve the quality of life of individuals.

Transcription factor7-like2 (TCF7L2) gene polymorphisms could case variants of TCF7L2 that are strongly associated with T2D. TCF7L2 is an important factor in pancreatic island function regulation (8). TCF7L2 as a transcription factor regulates glucagon and glucagon like peptide1 (GLP1) with a set-out proglucagon gene 
(GCG). It is transcribed in pancreas alpha cells, intestinal L cells, and the colon. GLP1 has potent effects on glucose mediated insulin secretion (GSIS), insulin gene expression, beta cell growth, and differentiation. Therefore, TCF7L2 could be a potential agent for T2D treatment (21).

TCF7L2 intron 4 (IVS IV) sequence variants are important to produce some functional transcript variants of TCF7L2 mRNA that exon 4 involves in it, like C>T rs7903146 (8). In the study of this variant, we did not find any significant allelic frequency difference between T2D and normal subjects but the TT homozygote genotype was significantly associated with T2D. Shokouhi et al. reported a significant susceptibility of T allele with T2D in the Iranian Kurdish ethnic group (22). Palizban et al. introduced TCF7L2 gene rs7903149 polymorphism as an important risk factor behind the development of T2D (23). Different studies reported that the risk of T2D development in homozygote carriers of TCF7L2 mutant variants was twice higher (24-26).

\section{Conclusion}

A functional study of TCF7L variants showed that some variations like T rs7903146 are associated with decreased insulin secretion $(26,27)$. Pharmacogenomics analysis reports showed that, in TCF7L2 T rs7903146 variant carriers with $\mathrm{T} 2 \mathrm{D}$, sulfonylurea treatment was not effective (26). The ENPP1 K121Q polymorphism is associated with insulin resistance and modulated the efficacy of lifestyle intervention on the incidence of T2DM (16). In conclusion, detection of genetic factors associated with T2D could help suggest a proper lifestyle and effective treatment. It was good for recognition of diabetes related disorders and controlling them.

\section{Acknowledgements}

This study was conducted in the molecular genetic laboratory of Islamic Azad University, Zanjan Branch, Zanjan, Iran as an MSc thesis project. We thank F. Ferdosi for assistance in experiments and sample preparation.

\section{Conflict of Interest}

Authors declare no conflict of interests.

\section{Author Contributions}

S.M. and A.E. designed the study, P.G. and S.M. performed molecular genetic experiments and analyzed data, S.M., and P.G. wrote the paper.

\section{References}

1. Bonnefond A, Froguel P, Vaxillaire M. The emerging genetics of type 2 diabetes. Trend Molec Med. 2010; 16(9): 407-16. [DOI:10.1016/j.molmed.2010.06.004] [PMID]

2. Sun X, Yu W, Hu C. Genetics of type 2 diabetes: insights into the pathogenesis and its clinical application. Bio Med Res Int. 2014; 2014: 1-15. [DOI:10.1155/2014/926713] [PMID] [PMCID]

3. Chaudhury A, Duvoor C, Dendi VSR, et al. Clinical review of antidiabetic drugs: Implications for type 2 diabetes mellitus management. Front Endocrinol. 2017; 8: 6. [DOI:10.3389/fendo.2017.00006] [PMID] [PMCID]

4. Mahmazi S, Parivar K, Rahnema M, Ohadi M. Calreticulin novel mutations in type 2 diabetes mellitus. Int J Diabetes Develop Count. 2013; 33(4): 219-25. [DOI:10.1007/s13410013-0152-0]

5. Association AD. 2. Classification and diagnosis of diabetes. Diabetes Care. 2016; 41: S13-S27. [DOI:10.2337/dc18S002] [PMID]

6. Lyssenko V, Groop L, Prasad RB. Genetics of type 2 diabetes: it matters from which parent we inherit the risk. Rev Diabet Stud. 2015; 12(3-4): 233-42. [DOI:10.1900/RDS.2015.12.233] [PMID] [PMCID]

7. Neve B, Le Bacquer O, Caron S, et al. Alternative human liver transcripts of TCF7L2 bind to the gluconeogenesis regulator HNF4 $\alpha$ at the protein level. Diabetologia. 2014; 57(4): 785-96. [DOI:10.1007/s00125-013-3154-z] [PMID]

8. Jin T. Current understanding on role of the Wnt signaling pathway effector TCF7L2 in glucose homeostasis. Endocrine Rev. 2016; 37(3): 254-77. [DOI:10.1210/er.20151146] [PMID]

9. Kasper J, Milton A, Smith A, et al. Cognitive deficits associated with a high-fat diet and insulin resistance are potentiated by overexpression of Ecto-nucleotide pyrophosphatase phosphodiesterase-1. Int J Dev Neuro Sci. 2018; 64: 48-53. [DOI:10.1016/j.ijdevneu.2017.03.011] [PMID] [PMCID]

10. Fajar JK. The association of ectonucleotide pyrophosphatase/phosphodiesterase 1 (ENPP1) K121Q gene polymorphism with the risk of type 2 diabetes mellitus in European, American, and African populations: A metaanalysis. J Health Sci. 2016; 6(2): 76-86. [DOI:10.17532/jhsci.2016.358]

11. Costanzo BV, Trischitta V, Di Paola R, et al. The Q allele variant (GLN121) of membrane glycoprotein PC-1 interacts with the insulin receptor and inhibits insulin signaling more effectively than the common $\mathrm{K}$ allele variant (LYS121). Diabetes. 2001; 50(4): 831-36. [DOI:10.2337/diabetes.50.4.831] [PMID]

12. Bhambhani G, Bhambhani RG, Thakor NC. Lipid profile of patients with diabetes mellitus: a cross sectional study. Int $\mathrm{J}$ Res Med Sci. 2015; 3(11): 3292-95. [DOI:10.18203/2320$\underline{6012 . i j r m s 20151179]}$ 
13. Daniel MJ. Lipid management in patients with type 2 diabetes. Am Health Drug Bene fits. 2011; 4(5): 312-22.

14. Li Y-y. ENPP1 K121Q polymorphism and type 2 diabetes mellitus in the Chinese population: a meta-analysis including 11855 subjects. Metabolism. 2012; 61(5): 625-33. [DOI:10.1016/j.metabol.2011.10.002] [PMID]

15. Bhatti JS, Bhatti G, Mastana S, Ralhan S, Joshi A, Tewari R. ENPP1/PC-1 K121Q polymorphism and genetic susceptibility to type 2 diabetes in North Indians. Molec Cell Biochem. 2010; 345(1-2): 249-57. [DOI:10.1007/s11010010-0579-2] [PMID]

16. Kang JY, Sung SH, Lee YJ, Choi TI, Choi SJ. Impact of ENPP1 K121Q on change of insulin resistance after webbased intervention in korean men with diabetes and impaired fasting glucose. J Korean Med Sci. 2014; 29(10): 1353-59. [DOI:10.3346/jkms.2014.29.10.1353] [PMID] [PMCID]

17. Matsha T, Fanampe B, Yako Y, et al. Association of the ENPP1 rs997509 polymorphism with obesity in South African mixed ancestry learners. East Afr Med J. 2010; 87(8): 323-9.

18. Prakash J, Mittal B, Awasthi S, Agarwal C, Srivastava N. K121Q ENPP1/PC-1 gene polymorphism is associated with insulin resistance in a North Indian population. J Genetic. 2013; 92(3): 571-76. [DOI:10.1007/s12041-013-0287-2]

19. Sortica DA, Buffon MP, Souza BM, et al. Association between the ENPP1 K121Q polymorphism and risk of diabetic kidney disease: A systematic review and metaanalysis. PloS one. 2015; 10(3): e0118416. [DOI:10.1371/journal.pone.0118416] [PMID] [PMCID]

20. Sumi S, Ramachandran S, RamanKutty V, et al. ENPP1 121Q functional variant enhances susceptibility to coronary artery disease in South Indian patients with type 2 diabetes mellitus. Mol Cell Biochem. 2017; 435(1-2): 67-72. [DOI:10.1007/s11010-017-3057-2] [PMID]
21. Hansson O, Zhou Y, Renström E, Osmark P. Molecular function of TCF7L2: Consequences of TCF7L2 splicing for molecular function and risk for type 2 diabetes. Current Diabete Report. 2010; 10(6): 444-51. [DOI:10.1007/s11892010-0149-8] [PMID]

22. Shokouhi S, Delpisheh A, Haghani K, Mahdizadeh M, Bakhtiyari S. Association of rs7903146, rs12255372, and rs290487 polymorphisms in TCF7L2 gene with type 2 diabetes in an Iranian Kurdish ethnic group. Clin Lab. 2014; 60(8): 1269-76. [DOI:10.7754/Clin.Lab.2013.130809]

23. Palizban A, Nikpour M, Salehi R, Maracy M-R. Association of a common variant in TCF7L2 gene with type 2 diabetes mellitus in a Persian population. Clin Experiment Med. 2012; 12(2): 115-19. [DOI:10.1007/s10238-011-0144-7] [PMID]

24. Tong Y, Lin Y, Zhang Y, et al. Association between TCF7L2gene polymorphisms and susceptibility to type 2 diabetes mellitus: a large human genome epidemiology (HuGE) review and meta-analysis. BMC Med Genet. 2009; 10: 15. [DOI:10.1186/1471-2350-10-15] [PMID] [PMCID]

25. Grant SF, Thorleifsson G, Reynisdottir I, et al. Variant of transcription factor 7-like 2 (TCF7L2) gene confers risk of type 2 diabetes. Nature Genetics. 2006; 38(3): 320-23. [DOI:10.1038/ng1732] [PMID]

26. Javorský M, Babjaková E, Klimčáková L, et al. Association between TCF7L2 genotype and glycemic control in diabetic patients treated with gliclazide. Int J Endocrinol. 2013; 2013: 374858. [DOI:10.1155/2013/374858] [PMID] [PMCID]

27. Florez JC, Jablonski KA, Bayley N, et al. TCF7L2 polymorphisms and progression to diabetes in the Diabetes Prevention Program. New Eng J Med. 2006; 355(3): 241-50. [DOI:10.1056/NEJMoa062418] [PMID] [PMCID]

\section{How to Cite This Article:}

Golbon P, Esmaeilzadeh A, Mahmazi S. Association of ENPP1 (K121Q rs 1044498) and TCF7L2 (C/T rs7903146) Gene Polymorphisms with Type2 Diabetes in Zanjan population (Northwest, Iran). J Adv Med Biomed Res. 2018; 26 (118) :9-14

Download citation:

$\underline{\text { BibTeX }}|\underline{\text { RIS }}| \underline{\text { EndNote }}|\underline{\text { Medlars }}| \underline{\text { ProCite }}|\underline{\text { Reference Manager }}| \underline{\text { RefWorks }}$

Send citation to:

Mendeley 2 Zotero :-1RefWorks RefWorks 